\title{
Formulation and Development of Aqueous Film Coating for Moisture Protection of Hygroscopic Herniaria glabra L. Tablets
}

\author{
(1) Hakim EL MABROUKI*, (1) Irina Evgenievna KAUKHOVA \\ Saint-Petersburg State Chemical Pharmaceutical University, Department of Industrial Technology of Drugs, Saint-Petersburg, Russia
}

\begin{abstract}
Objectives: The present study aims to develop a moisture-protective coating solution and use it to film coat hygroscopic Herniaria glabra L. tablets. Materials and Methods: Five coating formulations were developed and applied on $\mathrm{H}$. glabra core tablets in a fluidized-bed coating. The film-coated tablets were evaluated by appearance, percentage of moisture gain, disintegration time, and percent of drug release. Physicochemical properties and stability during storage of the best obtained coated tablets were studied.

Results: The results of this study showed that the film coating F5 containing 25\% hydroxypropyl methyl cellulose (HPMC), 20\% shellac, 10\% polyethylene glycol (PEG) 1500, 29.6\% PEG 4000, 5\% tween 80, 10\% titanium dioxide, and $0.4 \%$ acid red 2 offered good protection for coated tablets against moisture. Coated tablets showed physical and dissolution stability during storage.

Conclusion: A combination of hydrophilic polymer HPMC and hydrophobic polymer shellac is suitable for balancing moisture-protective properties and attaining the fast release of drugs. This study could make it worthwhile to develop a pharmaceutical moisture barrier film coating system for immediate release tablets. However, more studies will be needed to evaluate the moisture-resistant film further.
\end{abstract}

Key words: HPMC, shellac, moisture protection, coating, Herniaria glabra tablets

\section{INTRODUCTION}

Tablets are the most popular dosage form of the drugs in use today. However, tablets may contain moisture-sensitive active pharmaceutical ingredients (APIs). The stability of API in tablets during their shelf life is necessary to ensure its effectiveness. Thus, absorbing moisture can cause hydrolysis and oxidation, which conduct to the degradation of the active substances and consequently decrease in therapeutic efficiency of the medicine. Therefore, the most suitable is to protect the core tablets with a moisture protective film that could efficiently prevent water vapor from attaining the cores and hence prevent the hydrolytic degradation of API. ${ }^{2,3}$

Moisture protective films are used for protection from moisture and improve physical appearance, mechanical resistance, and masking unpleasant odors and tastes. ${ }^{4}$

A perfect coating film should exhibit various qualities to attain the function of the moisture barrier. Thus, the coating film should be uniform and smooth and guarantee the stability of the drug during the shelf life. Such a coating film should also possess an adequate thickness and low permeability to water vapor. 5

The use of the coating film with water-soluble polymers has seen great success in recent years due to the drawbacks of organic solvents (toxicity, pollution, and explosion hazards) utilized in water-insoluble polymers. ${ }^{6,7}$ Therefore, water-soluble polymers, including hydroxypropyl methyl cellulose (HPMC), hydroxyethyl cellulose, and polyvinyl alcohol, are widely used in moisture barrier coating. ${ }^{8}$

A coating film formed with entero-soluble polymers, such as shellac polymer, could efficiently provide moisture protection and enteric functionalities due to their insolubility at acidic and neutral $\mathrm{pH} .{ }^{9,10}$ Shellac polymer can be used in coating film to achieve enteric applications, immediate-release properties, taste masking, and seal coating. 
Different methods have been developed to test the moisture uptake of drugs. The most common method is to measure the weight increase of the dosages at various constant temperature and humidity conditions. Therefore, both uncoated and coated pharmaceutical dosages are investigated for their moisture uptake at these various humidity conditions created by a saturated salt.

Tablets containing Herniaria glabra L. extract, potassium citrate, and sodium citrate were developed in a laboratory to study their diuretic and antilithiasic effect.11-13 However, studies have shown that obtained tablets are moisture sensitives. Thus, absorbing moisture can cause degradation of the active substances and consequently reduce their therapeutic efficacy.

The objective of this study was to develop moisture barrier films based on HPMC and shellac polymers, to film coat hygroscopic $H$. glabra core tablets, and evaluate the moisture barrier properties of the films at different humidity conditions. Drug release of the coated tablets was investigated. In addition, the stability of the coated tablets during storage was also evaluated.

\section{MATERIALS AND METHODS}

\section{Chemicals and reagents}

H. glabra was supplied by herbs Morocco (Rabat, Morocco); potassium citrate, sodium citrate, schellac, lactose monohydrate, calcium stearate, tween 80, and titanium dioxide were provided by Merck (Darmstadt, Germany); HPMC 6FC was obtained from Dow Chemical Company (Midland, MI, USA); polyethylene glycol (PEG) 1500 and PEG 4000 was provided by Stepan Company (Northfield, USA), while stearic acid was received from Tianjin Damao Chemical Reagent Factory (Tianjin, China); acid red 2 was supplied by Spectrum Chemical (New Brunswick, USA).

\section{Preparation of film-coated Herniaria glabra tablets}

\section{Preparation of saponin-rich extract of Herniaria glabra}

H. glabra herb was initially defatted with petroleum ether in the Soxhlet apparatus and then extracted with ethanol $70 \%$ for 7 days by maceration. ${ }^{14}$ The obtained extract was purified from ballast and accompanying substances using the selective liquidliquid extraction method with organic solvents (cyclohexane, chloroform, and ethyl acetate) and then precipitated in cold acetone, obtaining purified saponin-rich extract. ${ }^{15}$ The obtained extract was dried at $60^{\circ} \mathrm{C}$.

\section{Preparation of core tablet}

The core tablet contains $50 \mathrm{mg}$ saponin-rich extract $H$. glabra, $100 \mathrm{mg}$ potassium citrate, $100 \mathrm{mg}$ sodium citrate, $245 \mathrm{mg}$ lactose, and $5 \mathrm{mg}$ calcium stearate was obtained by wet granulation method. All the ingredients were weighed correctly and sieved through a 20 mesh sieve. Saponin-rich extract $H$. glabra, potassium citrate, and sodium citrate as drug substances and lactose monohydrate as a diluent was loaded into a Laboratory High Shear Mixer Granulator (STE Techpharm, Spain) and mixed for 5 min. $^{16}$ The powder blend was granulated using purified water as granulating fluid. Purified water was sprayed onto the powders with $3 \mathrm{~g} / \mathrm{min}$ and $0.11 \mathrm{MPa}$ spray air pressure. During the spraying, the impeller speed was $600 \mathrm{rpm}$. The wet granules were air-dried in the Lab Fluid Bed Dryer (STREA-1, Aeromatic Fielder, Switzerland) at an inlet temperature of $60^{\circ} \mathrm{C}$ for 10 min..$^{17}$ The dried granules were milled through an $850 \mu \mathrm{m}$ sieve and lubricated for 5 min with calcium stearate, and stored for compression into tablets. The tablets were compressed with a single punch machine (Korsch EKO, Germany). The average weight of the tablets was $500.0 \mathrm{mg}$.

\section{Preparation of film-coating suspensions}

Five coating formulations were developed using HPMC and shellac as film-forming agents, stearic acid, PEG 1500 and 4000 as plasticizers, tween 80 as the surfactant, titanium dioxide as a pigment, and acid red 2 as colorant; detailed compositions were shown in the Tables 1 and 2.

Formulation $\mathrm{F} 1$ contained $8 \%$ shellac, $0.6 \%$ stearic acid, $6 \%$ PEG 4000, 0.4\% tween 80, 1.5\% $\mathrm{TiO}_{2}, 0.05 \%$ acid red 2 dye, $10 \%$ ammonia $25 \%$ and $73.45 \%$ distilled water. Polymeric shellac solution was obtained by dissolving $40 \mathrm{~g}$ shellac polymer in a mixture of $200 \mathrm{~mL}$ water and $50 \mathrm{~g} 25 \%$ ammoniated aqueous solution under stirring and heating at a temperature between $50-60^{\circ} \mathrm{C}^{18}$ The obtained polymer shellac solution was cooled to room temperature. $30 \mathrm{~g}$ PEG 4000, $2.0 \mathrm{~g}$ tween 80 , and $3.0 \mathrm{~g}$ stearic acid were added progressively and mixed to the polymeric shellac solution until evenly dispersed. Titanium dioxide $(7.5 \mathrm{~g}$ ) was dispersed in $100 \mathrm{~mL}$ purified water using a magnetic stirrer for 2 hours in a separate container. The obtained shellac mixture was thoroughly mixed with titanium dioxide suspension, $0.25 \mathrm{~g}$ acid red 2 dye, and remaining water under stirring for 60 minutes to obtain a homogenized distribution.

Formulation F2 contained 7.5\% shellac, 7.5\% PEG 4000, 0.5\% tween $80,1.5 \% \mathrm{TiO}_{2}, 0.05 \%$ acid red 2 dye, $10 \%$ ammonia $25 \%$ and $72.95 \%$ distilled water. Formulation F2 (not containing stearic acid) was prepared in the same way as F1.

Formulation F3 contained 6\% HPMC, 6\% PEG 4000, 0.3\% tween $80,1 \% \mathrm{TiO}_{2}, 0.05 \%$ acid red 2 dye and $86.65 \%$ distilled water. Polymeric HPMC solution was obtained by dissolving $30.0 \mathrm{~g}$ HPMC polymer in $300.0 \mathrm{~mL}$ purified water with magnetic stirring at $80^{\circ} \mathrm{C}$ for 60 minutes. The obtained polymeric HPMC solution was cooled to room temperature (RT) and mixed with 30.0 g PEG 4000 and 1.5 g tween 80 . In a separate container, 5.0 $\mathrm{g}$ titanium dioxide was dispersed in $100 \mathrm{~mL}$ purified water using a magnetic stirrer for 2 hours. The obtained HPMC mixture was mixed with titanium dioxide suspension, $0.25 \mathrm{~g}$ acid red 2 dye, and remaining water under stirring for 60 minutes to obtain a homogenized distribution.

Formulation F4 contained 2.4\% shellac, 3\% HPMC, 2.8\% PEG 4000, 1\% PEG 1500, 0.6\% tween 80, 1.2\% $\mathrm{TiO}_{2}, 0.05 \%$ acid red 2 dye, $4 \%$ ammonia $25 \%$ and $84.95 \%$ distilled water. Polymeric shellac solution (12.0 g shellac prepared in the same way as F1) was mixed with $14.0 \mathrm{~g}$ PEG 4000, $5.0 \mathrm{~g}$ PEG 1500, and $3.0 \mathrm{~g}$ tween 80 to obtain a homogenized shellac mixture. Polymeric HPMC solution (15.0 g HPMC prepared similarly to F3) was mixed with the shellac mixture, titanium dioxide suspension 
( $6.0 \mathrm{~g} \mathrm{TiO}_{2}$ ), $0.25 \mathrm{~g}$ acid red 2 dye, and remaining water under stirring for 60 minutes in order to obtain a homogenized distribution.

Formulation 5 contained $2.4 \%$ shellac, 3\% HPMC, 3.6\% PEG 4000, 1.2\% PEG 1500, 0.6\% tween 80, 1.2\% $\mathrm{TiO}_{2}, 0.05 \%$ acid red 2 dye, $4 \%$ ammonia $25 \%$ and $83.95 \%$ distilled water. Formulation F5 was prepared in the same way as F4.

The coating solutions were filtered through sieve number 140 , equivalent to $160 \mu \mathrm{m}$ (ASTM E-11, Cole Parmer, USA), and stored in an airtight container.

\section{Preparation of free films}

Free films were prepared by casting polymer solution onto glass petri dishes and placed in an oven at $50^{\circ} \mathrm{C}$ for $24 \mathrm{~h}$. Dried films were removed and cut carefully into strips with an average thickness of 200-300 $\mu \mathrm{m}$, a width of $10 \mathrm{~mm}$, and a length of $50 \mathrm{~mm}$. The free film was kept in a desiccator with $50 \% \mathrm{RH}$

\begin{tabular}{llllll}
\multicolumn{7}{l}{ Table 1. Composition of coating solutions (w/w\%) } \\
Component & F1 & F2 & F3 & F4 & F5 \\
\hline Shellac & 8.0 & 7.5 & - & 2.4 & 2.4 \\
\hline Stearic acid & 0.6 & $-{ }^{a}$ & - & - & - \\
\hline HPMC $^{b}$ 6FC & - & - & 6.0 & 3.0 & 3.0 \\
\hline PEG $^{c}$ 4000 & 6.0 & 7.5 & 6.0 & 2.8 & 3.6 \\
\hline PEG 1500 & - & - & - & 1.0 & 1.2 \\
\hline Tween 80 & 0.4 & 0.5 & 0.3 & 0.6 & 0.6 \\
\hline TiO 2 & 1.5 & 1.5 & 1.0 & 1.2 & 1.2 \\
\hline Acid red 2 & 0.05 & 0.05 & 0.05 & 0.05 & 0.05 \\
\hline Ammonia 25\% & 10.0 & 10.0 & - & 4.0 & 4.0 \\
\hline Distilled water & 73.45 & 72.95 & 86.65 & 84.95 & 83.95 \\
\hline
\end{tabular}

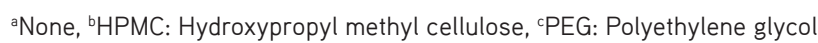

at RT until mechanical analyses were performed. Mechanical properties of the films, including tensile strength and elongation at break, were evaluated by a texture analyzer (TA-XT plus, UK) using a $50 \mathrm{~N}$ load cell and crosshead speed of $5 \mathrm{~mm} / \mathrm{min}$.

\section{Coating process}

The coating of the tablets was carried out in a fluid bed coater (Strea-1 Aeromatic Fielder, Switzerland) and the coating parameters were as follows: Batch size $500.0 \mathrm{~g}$, inlet air temperature $60^{\circ} \mathrm{C}$, outlet air temperature $45^{\circ} \mathrm{C}$, airflow 90 $\mathrm{m}^{3} / \mathrm{h}$, atomizing air pressure 2.0 bar, spray rate $3 \mathrm{~g} / \mathrm{min}$, drying temperature $50^{\circ} \mathrm{C}$ and drying time $15 \mathrm{~min}$. The tablets were coated until a weight gain of $6 \% \mathrm{w} / \mathrm{w}$. The coating solution was stirred continuously during the overcoating process.

\section{Evaluation of tablets core and coated tablets}

The thickness, friability, hardness, and disintegration time of the core tablets and coated tablets were studied according to the methods described in the Russian Pharmacopoeia 14. ${ }^{19}$ The thickness was determined with a micrometer (moore and right 1965B, UK), the friability was determined with a friabilator (Erweka TA 100, Germany), the hardness was measured using a hardness tester (Erweka TBH 125, Germany) and the disintegration time was studied in distilled water (disintegration medium) at $37 \pm 0.5^{\circ} \mathrm{C}$ using disintegration tester (Erweka ZT 120, Germany).

\section{Dissolution test of tablets}

The dissolution test was performed using the Russian Pharmacopeia 14 paddle method. ${ }^{20}$ Drug release was measured in Erweka dissolution tester (DT 720, Germany) using distilled water as the dissolution medium, maintained at $37 \pm 0.5^{\circ} \mathrm{C}$ and agitated at $50 \mathrm{rpm}(n=6)$. The samples were withdrawn at 5,10 , $15,20,30,45$, and $60 \mathrm{~min}$.

Drug release of saponins was determined spectrophotometrically based on the method of Hiai et al. ${ }^{21}$ To $0.5 \mathrm{~mL}$ of sample and

Table 2. Compositions of film-coating (\%)

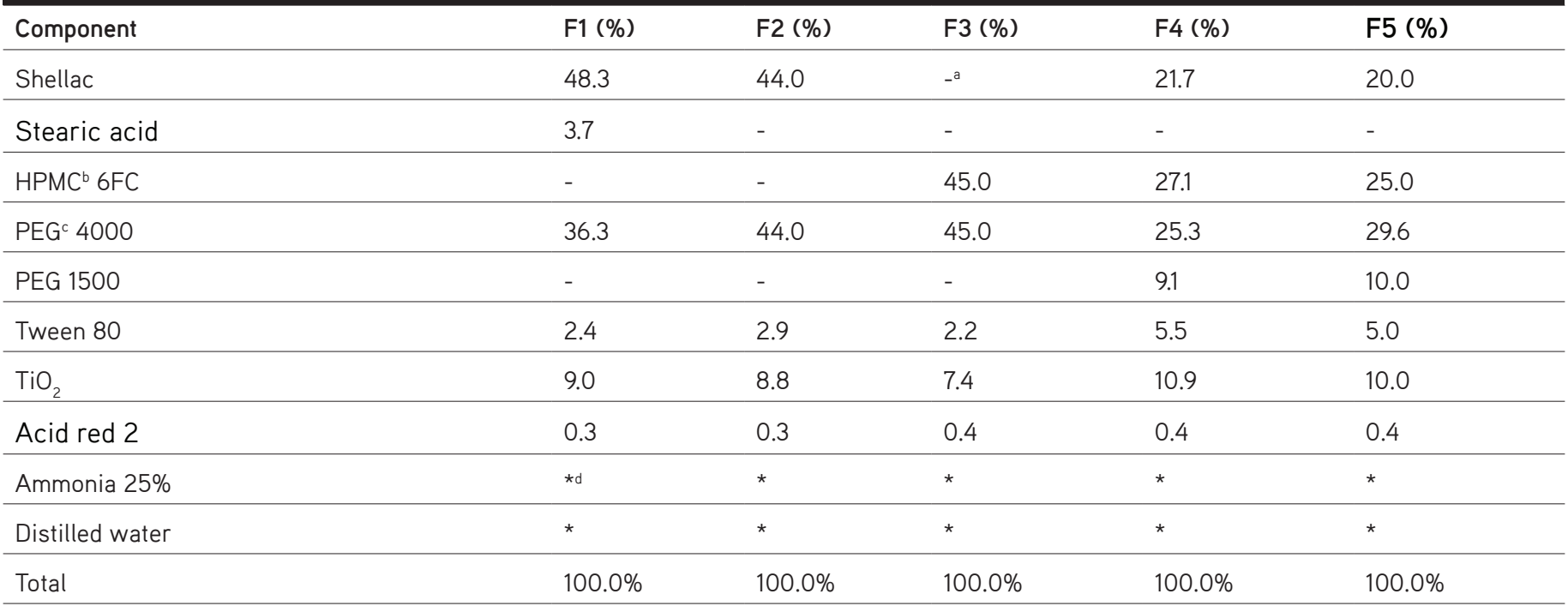

aNone, bHPMC: Hydroxypropyl methyl cellulose, 'PEG: Polyethylene glycol, dDistilled water and ammonia $25 \%$ are volatile components, which do not remain in the film coating 
standard (escin), $0.5 \mathrm{~mL}$ of $8 \%$ vanillin solution. Then $5.0 \mathrm{~mL}$ of $72 \%$ sulfuric acid were added and mixed well in an ice water bath. The mixture was warmed in a bath at $60^{\circ} \mathrm{C}$ for $10 \mathrm{~min}$, then cooled in water at the ambient temperature for $5 \mathrm{~min}$. The absorbance of the standard and samples was measured at 560 nm using a ultraviolet 1240 spectrophotometer from Shimadzu, Japan.

Preparation of reagents: $8 \%(\mathrm{w} / \mathrm{v})$ vanillin solution: $800 \mathrm{mg}$ of vanillin was dissolved in $10 \mathrm{~mL}$ of $99.5 \%$ ethanol. Prepared freshly for each determination.

$72 \%(\mathrm{v} / \mathrm{v}$ ) sulfuric acid: To $28 \mathrm{~mL}$ of deionized water, $72 \mathrm{~mL}$ of sulfuric acid was added.

Drug release of citrates was determined using the nonaqueous acid-base titrimetry method described in European Pharmacopeia $8 .{ }^{22} 20 \mathrm{~mL}$ of sample was evaporated gently on a hot plate until dryness, then dissolved in $20 \mathrm{~mL}$ of anhydrous acetic acid, heating to about $50^{\circ} \mathrm{C}$. It allowed cooling. $0.25 \mathrm{~mL}$ of naphtholbenzein solution as an indicator was added, and the solution was titrated with $0.1 \mathrm{~N}$ perchloric acid until a green color was obtained.

Preparation of reagents: Preparation of anhydrous acetic acid: $104 \mathrm{~mL}$ of acetic anhydride poured into glacial acetic acid in small portions with stirring. The acid container was left to stand for about a day.

Preparation of $0.1 \mathrm{~N}$ titrated perchloric acid solution in anhydrous acetic acid: Approximately $8.5 \mathrm{~mL}$ of $72 \%$ perchloric acid was dissolved in $100 \mathrm{~mL}$ of anhydrous acetic acid, about $30 \mathrm{~mL}$ of acetic anhydride was added in small portions with constant cooling of the solution to bind water. The bottle was closed with a cork and left for a day in a dark place, then the volume of the solution was brought to 1 liter.

\section{Moisture uptake of tablets}

Moisture uptake of the tablets was determined by placing the tablets in desiccators of $25^{\circ} \mathrm{C} / 75 \% \mathrm{RH}$, saturated sodium chloride solution, and $25^{\circ} \mathrm{C} / 91 \% \mathrm{RH}$, saturated potassium nitrate solution. ${ }^{23}$ Weight gain was measured at predetermined time points.

\section{Stability test of coated tablets}

The samples of coated tablets were blister packed in aluminum using the packing machine DP-210 (Wenzhou T\&D Packaging Machinery Factory, China). Stability studies were realized according to ICH guidelines. ${ }^{24}$ Tests were conducted under RT and accelerated stability conditions. The samples designed for RT were kept at $30 \pm 2^{\circ} \mathrm{C}$ and $65 \pm 5 \%$ relative humidity, while the accelerated stability samples were kept at $40 \pm 2^{\circ} \mathrm{C}$ and 75 $\pm 5 \% \mathrm{RH}$ in a humidity chamber (Binder KBF 115 , Germany). The RT samples were tested at $0,3,6,9$, and 12 months. The accelerated stability samples were tested at $0,1,2,3$, and 6 months. The coated tablets were tested for their physical appearance, hardness, friability, disintegration, and dissolution during storage.

\section{Ethics committee approval}

In this study, ethics committee approval is not required.

\section{Statistical analysis}

In this study, statistical data was not used.

\section{RESULTS AND DISCUSSION}

It has been shown that coatings affect the physicochemical properties of the tablet to varying degrees and these changes are suggestive of the effect of the coating materials. ${ }^{25,26}$ The moisture uptake behavior of coated tablets exposed to different relative humidity conditions can be utilized to measure the ability of a film coating to protect the core tablet against moisture. ${ }^{27}$ Thus, core tablets of $\mathrm{H}$. glabra were coated using the prepared coating solutions (Tables 1,2). The results of the tested parameters are presented in Table 3 and Figures 1-3.

\section{For formulations F1 and F2}

Tablets coated with formulation F1 (TCF1) showed an excellent physical appearance with a smooth surface. The coated tablets exhibited the best moisture protection compared to other coated tablets (moisture gain of $5.1 \%$ at $75 \% \mathrm{RH}$ and 6.4 at $90 \% \mathrm{RH}$ ). Coated tablets' disintegration time was increased compared to core tablets (from $3 \mathrm{~min}$ in core tablets to $25 \mathrm{~min}$ in coated tablets). The dissolution profile of TCF1 showed a decrease in drug release ( $80.2 \%$ of saponins and $84.4 \%$ of citrates).

TCF2 also showed an excellent physical appearance and good moisture protection. Removing stearic acid from F2 has slightly decreased disintegration time (22 $\mathrm{min})$ and increased dissolution of coated tablets ( $82.3 \%$ of saponins and $87.2 \%$ of citrates).

Free shellac films F1 and F2 presented lower tensile strength and higher elongation (Figure 1).

Interestingly, shellac-coated tablets showed the lowest moisture uptake at $75 \%$ and $90 \%$ relative humidity (Figure 2 ). However,

Table 3. Physicochemical properties of uncoated and coated Herniaria glabra tablets

\begin{tabular}{lllll} 
Formulation & Disintegration $(\mathrm{min})$ & Saponin release (\%) & Citrate release (\%) & Physical appearance \\
\hline Tablet cores & $3 \pm 1$ & $94.1 \pm 1.2$ & $96.0 \pm 1.3$ & - \\
\hline CTF1 & $25 \pm 1$ & $80.2 \pm 1.5$ & $84.4 \pm 0.5$ & Smooth shiny surface \\
\hline CTF2 & $22 \pm 1$ & $82.3 \pm 0.7$ & $87.2 \pm 1.2$ & Smooth shiny surface \\
\hline CTF3 & $7 \pm 1$ & $90.2 \pm 1.2$ & $93.2 \pm 0.9$ & Signs of cracking \\
\hline CTF4 & $15 \pm 1$ & $86.1 \pm 0.9$ & $89.3 \pm 1.1$ & Signs of cracking \\
\hline CTF5 & $15 \pm 1$ & $88.0 \pm 1.6$ & $90.6 \pm 0.8$ & Smooth shiny surface \\
\hline
\end{tabular}




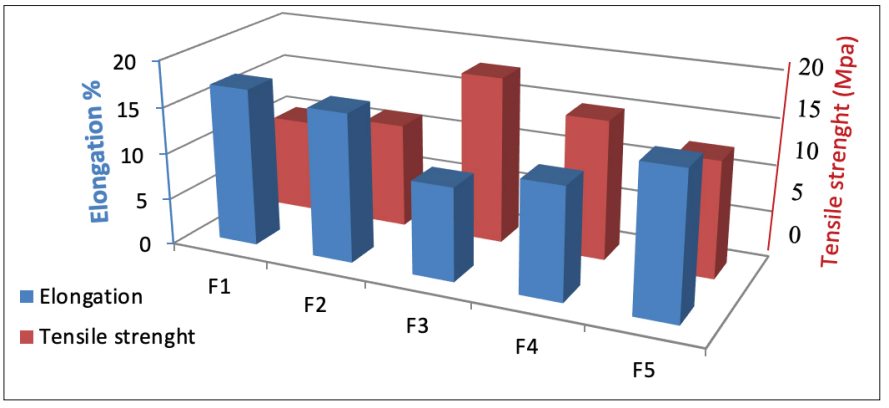

Figure 1. Tensile strength and percentage elongation of free films

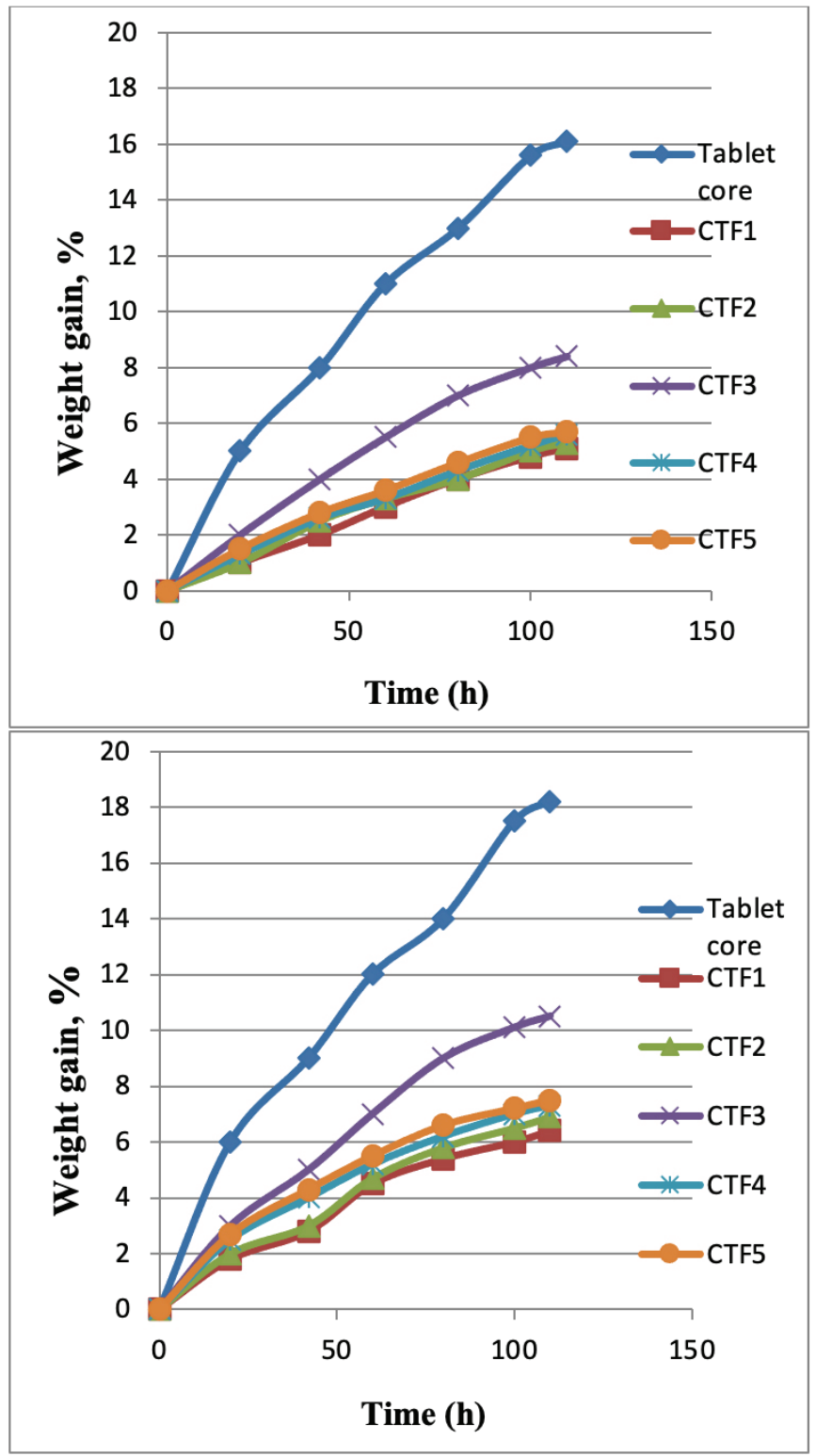

Figure 2. Percent moisture (weight) gain of coated tablets at $25^{\circ} / 75 \% \mathrm{RH}$ and at $25^{\circ} / 90 \% \mathrm{RH}$

shellac coating led to a long disintegration time and reduced the resulting drug release rate considerably. Therefore, it is convincing to suggest that these findings can be attributed to shellac's poor water solubility and the hydrophobic character of

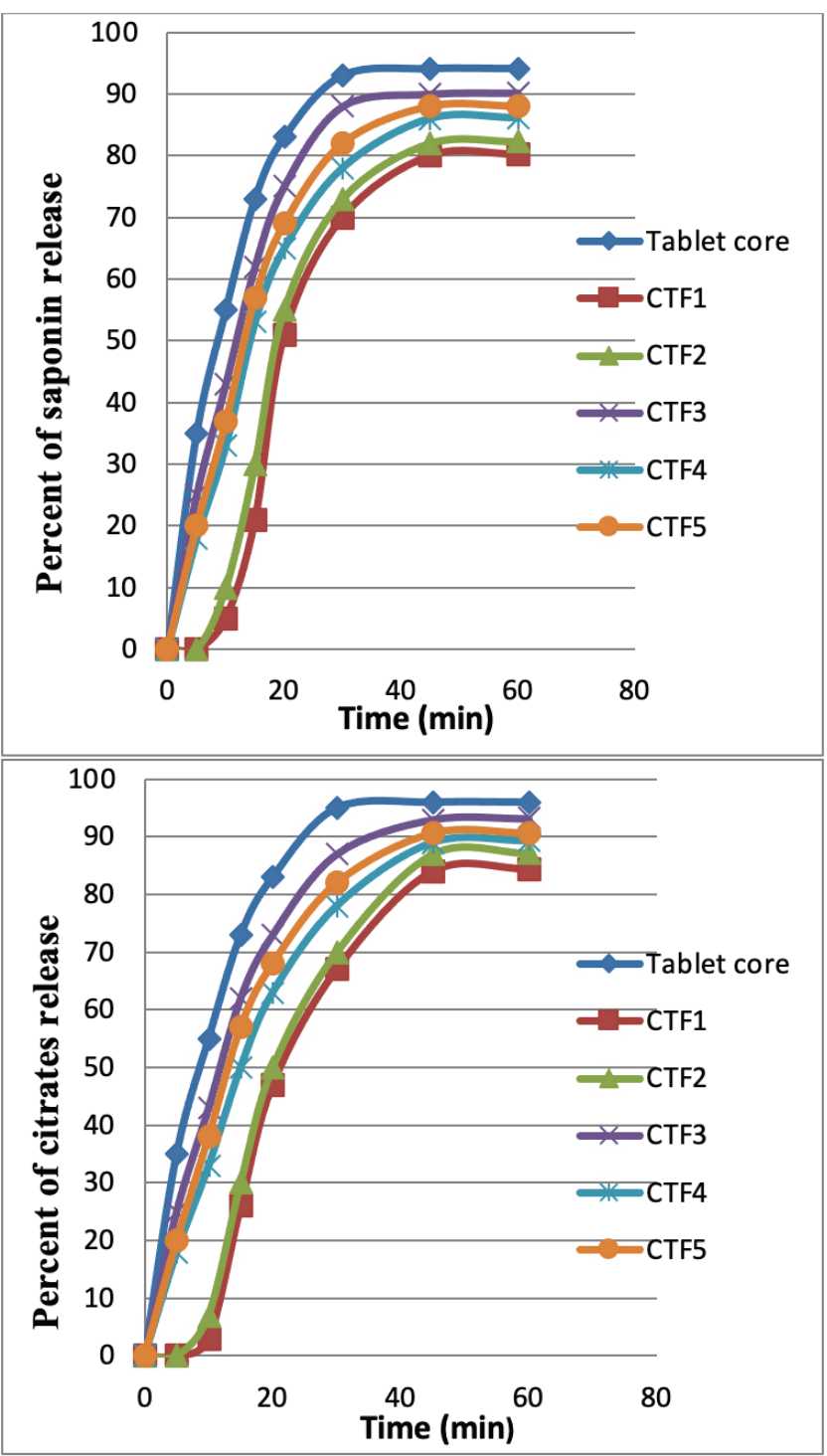

Figure 3. Drug release of $\mathrm{H}$. glabra-coated tablets with different coating solutions (F1, F2, F3, F4, and F5)

the stearic acid (in F1), which have led to the form of a coating film with low permeability. ${ }^{28-30}$

\section{For formulation F3}

TCF3 showed the shortest disintegration time $(7 \mathrm{~min})$ and exhibited the best drug release $(90.2 \%$ of saponins and $93.1 \%$ of citrates) in comparison to other coated tablets. However, coated tablets manifested high moisture uptake (moisture gain of $8.4 \%$ at $75 \% \mathrm{RH}$ and $10.5 \%$ at $90 \% \mathrm{RH}$ ) and showed signs of cracking.

Therefore, the tablets coated with HPMC film showed higher moisture uptake than tablets coated with shellac film, indicating that HPMC has a lower potential for moisture protection than shellac. This is a result of the hydrophilic nature of the HPMC film. Then, the HPMC polymer, a hydrocolloid, absorbs water molecules due to hydrogen bonding with water molecules and itself. As a result, when the film is exposed to water/moisture, it tends to allow a water vapor permeability. ${ }^{31}$ 


\section{For formulations $\mathrm{F} 4$ and $\mathrm{F} 5$}

TCF4 showed lower water uptake rates than HPMC-coated tablets (moisture gain $5.6 \%$ at $75 \% \mathrm{RH}$ and $7.3 \%$ at $90 \% \mathrm{RH}$ ). The disintegration time of TCF 4 was reduced $(15 \mathrm{~min})$ in comparison to HPMC-coated tablets. The dissolution profile of TCF4 showed an increase in drug release $(86.1 \%$ of saponins and $89.3 \%$ of citrates) in comparison to HPMC-coated tablets. However, TCF 4 has shown signs of cracking attributed to a lack of plasticizer concentration in film.

Increasing concentrations of plasticizers, 1.2\% PEG 1500 and 3.6\% PEG 4000 in coating solution F5 (10\% PEG 1500 and 29.6\% PEG 4000 in film coating F5), have disappeared and wellcoated tablets (TCF5) with smooth surfaces were obtained. Increasing the number of plasticizers has also led to a decrease in tensile strength and increased percent elongation (Figure 1). TCF5 showed a low moisture uptake. Thus, the weight gain was decreased from $16.1 \%$ of core tablets to $5.7 \%$ of TCF5 at $75 \%$ $\mathrm{RH}$ and from $18.2 \%$ of core tablets to $7.5 \%$ of TCF 5 at $90 \% \mathrm{RH}$.

In the shellac-HPMC composite film, shellac is a hydrophobic component that repels water molecules from forming a bond

Table 4. Physicochemical properties of uncoated and filmcoating Herniaria glabra tablets CTF5

\begin{tabular}{lll} 
& Uncoated & CTF5 \\
\hline Average weight of tablet $(\mathrm{mg})$ & $500.0 \pm 1.7$ & $530.0 \pm 0.8$ \\
\hline Diameter $(\mathrm{mm})$ & $11.0 \pm 0.4$ & $11.5 \pm 0.5$ \\
\hline Thickness $(\mathrm{mm})$ & $3.11 \pm 0.12$ & $3.35 \pm 0.14$ \\
\hline Hardness $(\mathrm{n})$ & $12.1 \pm 0.8$ & $12.4 \pm 0.7$ \\
\hline Friability $(\%)$ & 0.15 & 0.12 \\
\hline Disintegration time (min) & $3 \pm 1$ & $15 \pm 1$ \\
\hline Saponin content (\%) & $94.1 \pm 1.2$ & $88.0 \pm 1.6$ \\
\hline Citrate content (\%) & $96.0 \pm 1.3$ & $90.6 \pm 0.8$ \\
\hline
\end{tabular}

due to its hydrophobicity and hence reduces the permeability of water vapor through the composite film. ${ }^{32,33}$

TCF5 showed a satisfactory disintegration time within 15 min, and drug release achieved $88 \%$ of saponins and $90.6 \%$ of citrates which complied with the Russian dissolution requirements.

Therefore, the combination of $3 \%$ HPMC and $2.4 \%$ shellac in coating solution ( $25 \%$ HPMC and $29.6 \%$ shellac in film coating) has led to good protection for coated tablets against moisture and provided satisfactory dissolution.

According to these findings, the formulation F5 showed the most satisfactory results and was selected as an optimized formulation after comparative evaluation.

The properties of uncoated and coated tablets can be seen in Table 4. TCF5 showed a slight increase in hardness and a decrease in friability. The tablets' weight variation also decreased, which is indicative of the excellent coating uniformity provided by the fluid bed process. The disintegration time was increased from $3 \mathrm{~min}$ (core) to $15 \mathrm{~min}$. From the results, uncoated and coated tablets showed suitable characteristics which complied with the Russian Pharmacopoeia 14.

\section{Stability studies}

CTF5 was stored in a stability chamber with controlled temperature and humidity to study their stability. Thus, physicochemical properties were studied. The results are shown in Table 5.

Long-term and accelerated stability studies showed no major change in physical characteristics, hardness, friability, and disintegration of coated tablets. Drug release was within acceptable limits and complied with the Russian dissolution requirements. Thus, CTF5 was stable under stability testing conditions.

\section{CONCLUSION}

Hydrophilic polymer HPMC and hydrophobic polymer shellac are suitable for balancing moisture-protective properties and

Table 5. Stability testing of Herniaria glabra coated tablets at room temperature and under accelerated conditions

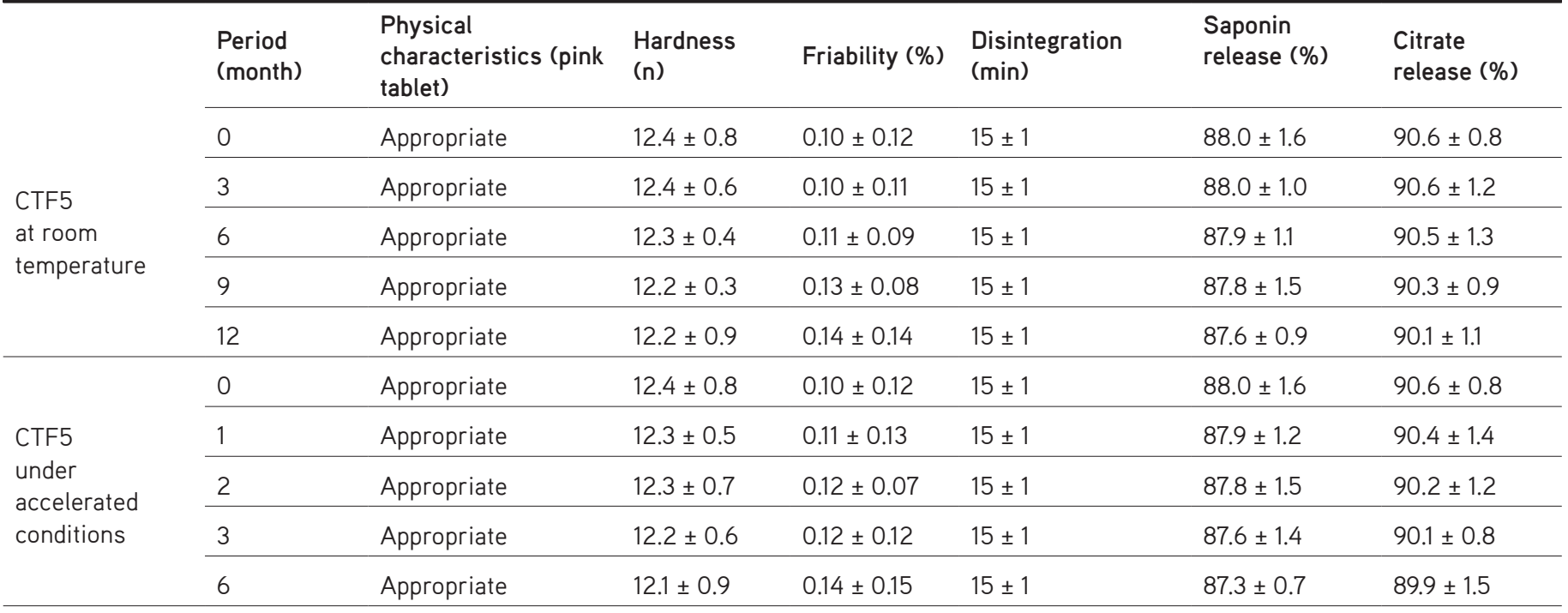


attaining fast-release drugs. The results of this study showed that formulation of film coating containing 25\% HPMC and $20 \%$ shellac as film-forming agent, 10\% PEG 1500 and 29.6\% PEG 4000 as plasticizers, $5 \%$ tween 80 as a surfactant, $10 \%$ titanium dioxide as pigment and $0.4 \%$ acid red 2 as colorant offered good protection for coated $H$. glabra tablets against moisture. Moreover, coated tablets showed physical and dissolution stability during storage. This study could make it worthwhile to develop a pharmaceutical moisture barrier film coating system for immediate release tablets. However, more studies will be needed to evaluate the moisture-resistant film further.

\section{Ethics}

Ethics Committee Approval: Approval is not required for this study.

Informed Consent: Informed consent is not required for this study.

Peer-review: Externally peer-reviewed.

\section{Authorship Contributions}

Concept: H.E.M., I.E.K., Design: H.E.M., Data Collection or Processing: H.E.M., Analysis or Interpretation: H.E.M., I.E.K., Literature Search: H.E.M., Writing: H.E.M.

Conflict of Interest: No conflict of interest was declared by the authors.

Financial Disclosure: The authors declared that this study received no financial support.

\section{REFERENCES}

1. Joshi S, Petereit HU. Film coatings for taste masking and moisture protection. Int J Pharm. 2013;457:395-406.

2. Haleblian JK, Goodhart FW. Pharmaceutical sciences-1974: literature review of pharmaceutics. J Pharm Sci. 1975;64:1085-1148.

3. Du J, Hoag SW. The influence of excipients on the stability of the moisture sensitive drugs aspirin and niacinamide: comparison of tablets containing lactose monohydrate with tablets containing anhydrous lactose. Pharm Dev Technol. 2001;6:159-166.

4. Gong Y, Zha Q, Li L, Liu Y, Yang B, Liu L, Lu A, Lin Y, Jiang M. Efficacy and safety of fufangkushen colon-coated capsule in the treatment of ulcerative colitis compared with mesalazine: a double-blinded and randomized study. J Ethnopharmacol. 2012;141:592-598.

5. Guo JH, Robertson RE, Amidon GL. Influence of physical aging on mechanical properties of polymer free films: the prediction of longterm aging effects on the water permeability and dissolution rate of polymer film-coated tablets. Pharm Res. 1991;8:1500-1504.

6. Uzma N, Salar BM, Kumar BS, Aziz N, David MA, Reddy VD. Impact of organic solvents and environmental pollutants on the physiological function in petrol filling workers. Int $J$ Environ Res Public Health. 2008;5:139-146.

7. Joshi D, Adhikari N. An overview on common organic solvents and their toxicity. J Pharm Res Int. 2019;28:1-18.

8. Yang Q, Yuan F, Xu L, Yan Q, Yang Y, Wu D, Guo F, Yang G. An update of moisture barrier coating for drug delivery. Pharmaceutics. 2019;11:436.
9. Al-Gousous J, Penning M, Langguth P. Molecular insights into shellac film coats from different aqueous shellac salt solutions and effect on disintegration of enteric-coated soft gelatin capsules. Int J Pharm. 2015:484:283-291.

10. De Leo V, Milano F, Mancini E, Comparelli R, Giotta L, Nacci A, Longobardi F, Garbetta A, Agostiano A, Catucci L. Encapsulation of curcuminloaded liposomes for colonic drug delivery in a $\mathrm{pH}$-responsive polymer cluster using a pH-driven and organic solvent-free process. Molecules. 2018;23:739

11. Bellakhdar J. Plantes Médicinales au Maghreb et soins de base. Précis de phytothérapie moderne. Editions le Fennec Casablanca; 2006:180.

12. Rhiouani H, El-Hilaly J, Israili ZH, Lyoussi B. Acute and sub-chronic toxicity of an aqueous extract of the leaves of Herniaria glabra in rodents. J Ethnopharmacol. 2008;118:378-386.

13. Phillips R, Hanchanale VS, Myatt A, Somani B, Nabi G, Biyani CS. Citrate salts for preventing and treating calcium containing kidney stones in adults. Cochrane Database Syst Rev. 2015;10:CD010057.

14. Hostettmann K, Marston A. Chemistry and Pharmacology of Natural Products- Saponins. Cambridge University Press; 1995:146.

15. Chua LS, Lau CH, Chew CY, Dawood DAS. Solvent fractionation and acetone precipitation for crude saponins from Eurycoma longifolia extract. Molecules. 2019;24:1416.

16. Parikh DM, Gokhale R, Sun Y, Shukla AJ. High-shear granulation. Handbook of pharmaceutical granulation technology. ( $2^{\text {nd }}$ ed). Taylor \& Francis; North Carolina; 2005:195-224.

17. Parikh DM, Mogavero M. Fluid bed drying. Handbook of Pharmaceutical Granulation Technology. ( $2^{\text {nd }}$ ed). Taylor \& Francis; North Carolina; 2005:265-268.

18. Redlick AB, Cherry Hill, Michael NJ. Secora.Pharmaceutical tablets coated with wax-free ammonia solubilized water soluble shellac, U.S. Pat. 3,390,049, 25 Jun 1964.

19. Russian Pharmacopoeia, $14^{\text {th }}$ edition, 2018; 2: 2111-2163.

20. Russian Pharmacopoeia, 14 $4^{\text {th }}$ edition, 2018; 2: 2164-2174

21. Hiai S, Oura H, Nakajima T. Color reaction of some sapogenins and saponins with vanillin and sulfuric acid. Planta Med. 1976;29:116-122.

22. European Pharmacopeia, $8^{\text {th }}$ edition, 2014; 3066

23. Vertucci CW, Roos EE. Theoretical basis of protocols for seed storage II. The influence of temperature on optimal moisture levels. Seed Sci Res. 1993;3:201-213.

24. International Conference on Harmonisation of Technical Requirements for Registration of Pharmaceuticals for Human Use. ICH Harmonised Tripartite Guideline, Stability testing of new drug substances and products Q1A (R2). 2003. https://database.ich.org/sites/default/files/ Q1A\%28R2\%29\%20Guideline.pdf

25. Rhodes $\mathrm{CT}$, Porter SC. Coatings for controlled-release drug delivery systems. Drug Dev Ind Pharm. 1998;24:1139-1154.

26. Wheatley TA. Water soluble cellulose acetate: a versatile polymer for film coating. Drug Dev Ind Pharm. 2007;33:281-290.

27. Pearnchob N, Siepmann J, Bodmeier R. Pharmaceutical applications of shellac: moisture-protective and taste-masking coatings and extendedrelease matrix tablets. Drug Dev Ind Pharm. 2003;29:925-938.

28. Farag Y, Leopold CS. Physicochemical properties of various shellac types. Dissolution technologies. 2007;16:33-39. http://dissolutiontech. com/DTresour/200905Articles/DT200905_A04.pdf 
29. Limmatvapirat S, Limmatvapirat C, Puttipipatkhachorn S, Nuntanid, J, Luandana-Anan M. Enhanced enteric properties and stability of shellac films through composite salts formation. Eur J Pharm Biopharm. 2007;67:690-698.

30. Schindler WD, Hauser PJ. Repellent finishes. Chemical Finishing of Textiles. 2004:74-86. https://www.elsevier.com/books/chemicalfinishing-of-textiles/schindler/978-1-85573-905-5

31. Asrar S. Development and characterization of shellac-hydroxypropyl methyl cellulose composite films with acid catalyst. All Theses. 2012:1438.https://tigerprints.clemson.edu/cgi/viewcontent. cgi?article $=2438 \&$ context=all_theses

32. Nelson KL, Fennema OR. Methylcellulose films to prevent lipid migration in confectionery products. J Food Sci. 1991;56:504-509.

33. Kester J, Fennema O. Edible films and coatings - a review. Food Technol. 1986;40:47-59. 